\title{
Changing the restaurant food environment to improve cardiovascular health in a rural community: implementation and evaluation of the Heart of New Ulm restaurant programme
}

\author{
Rebecca Lindberg ${ }^{1, *}$, Abbey C Sidebottom ${ }^{2}$, Brigitte $\mathrm{McCoo}^{2}$, Raquel F Pereira ${ }^{1}$, \\ Arthur Sillah ${ }^{2}$ and Jackie L Boucher ${ }^{3}$ \\ ${ }^{1}$ Minneapolis Heart Institute Foundation, 920 East 28th Street, Suite 100, Minneapolis, MN 55407, USA: \\ ${ }^{2}$ Division of Applied Research, Allina Health, Minneapolis, MN, USA: ${ }^{3}$ Children's HeartLink, Minneapolis, MN, USA
}

Submitted 26 May 2017: Final revision received 5 0ctober 2017: Accepted 1 November 2017: First published online 10 January 2018

\begin{abstract}
Objective: The goals of the present study were to: (i) describe the implementation of a programme to improve the restaurant food environment in a rural community; and (ii) describe how practices changed in community restaurants.

Design: The intervention included a baseline assessment of all community restaurants ( $n$ 32) and a report on how they could increase the availability and promotion of healthful options. The assessment focused on sixteen healthy practices (HP) derived from the Nutrition Environment Measures Survey for Restaurants. Restaurants were invited to participate at gold, silver or bronze levels based on the number of HP attained. Participating restaurants received dietitian consultation, staff training and promotion of the restaurant. All community restaurants were reassessed 1.5 years after baseline.

Setting: The restaurant programme was part of the Heart of New Ulm Project, a community-based CVD prevention programme in a rural community.

Subjects: All community restaurants ( $n$ 32) were included in the study.

Results: Over one-third (38\%) of community restaurants participated in the programme. At baseline, $22 \%$ achieved at least a bronze level. This increased to $38 \%$ at follow-up with most of the improvement among participating restaurants that were independently owned. Across all restaurants in the community, the HP showing the most improvement included availability of non-fried vegetables (63-84\%), fruits (41-53\%), smaller portions and whole grains.

Conclusions: Findings demonstrate successes and challenges of improving healthful food availability and promotion in a community-wide restaurant programme.
\end{abstract}

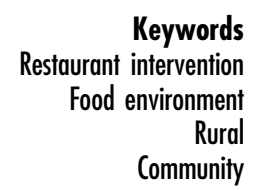

Obesity and overweight are a major public health concern in the USA, with $69 \%$ prevalence of obesity or overweight among adults ${ }^{(1,2)}$. Exploration of the role of the restaurant food environment includes studies of access, healthful food availability and frequency of eating out, as well as the impact of consumer nutrition information on outcomes of diet quality, energy intake and BMI. Studies examining access to fast food and BMI have mixed findings with some showing an increased BMI among residents of communities with higher prevalence of or closer proximity to fast-food restaurants, while other studies find no association ${ }^{(3,4)}$. Studies examining frequency of eating out have found that increased eating out may be associated with rising prevalence of overweight and obesity because of higher energy intake and poorer diet quality in restaurants ${ }^{(5,6)}$.
Specifically, meals eaten away from home have been shown to promote increased energy intake and poorer diet quality $^{(7)}$ as a result of larger portion sizes ${ }^{(8,9)}$, fewer fruits and vegetables, and increased consumption of foods higher in fat and sodium and lower in fibre ${ }^{(10)}$. A report by the US Department of Agriculture estimates that among people who eat one meal out per week, daily energy intake is increased by $561 \mathrm{~kJ}(134 \mathrm{kcal})$ and diet quality is lowered enough to switch their diet classification from 'fair' to 'poor', (7).

Rural areas pose an even greater concern due to the higher prevalence of obesity and CVD in rural areas and the reduced availability of healthful food options ${ }^{(11-15)}$. Although 60 million Americans live in rural areas ${ }^{(16)}$, few studies have evaluated the restaurant food environment or 
tested restaurant interventions in rural areas ${ }^{(17)}$. To date, most rural restaurant environment research has focused on access to and consumption of fast food ${ }^{(18,19)}$.

While there is evidence of the associations between the restaurant food environment and increased energy intake and reduced diet quality, and agreement among public health professionals that intervening in the food environment holds great potential for improving health outcomes ${ }^{(20-22)}$, limited research is available on effective interventions in restaurants. Interventions that have been tested include menu labelling ${ }^{(23,24)}$, manipulating prices of healthier options ${ }^{(25)}$, increased point-of-purchase promotion (verbal and/or visual) of healthier menu options in-house ${ }^{(26,27)}$ and patron estimation of energy (calorie) content of menu items ${ }^{(28)}$. Typically, studies on these interventions have been conducted in the context of one restaurant or cafeteria, or a group of specific types of restaurant. To date, limited research has been conducted with a goal of improving the overall food environment of all restaurants in a single community. Community-based restaurant intervention research to date includes studies promoting accessibility of healthful food options in rural restaurants and supermarkets ${ }^{(29)}$, investigating the impact of advertising for healthful food options in rural restaurants ${ }^{(26)}$ and cafeteria menu energy (calorie) labelling to investigate the effect of labelling on food choices ${ }^{(30)}$. Other observational studies have assessed the healthfulness of restaurant menu offerings ${ }^{(23,31,32)}$, but have not extensively intervened and reached throughout an entire community. Evidence about effective community-based strategies to promote healthful eating in restaurants is lacking, especially for rural areas ${ }^{(17)}$. A review evaluated community-based restaurant interventions on nine categories and found the most promising intervention strategy was combining point-of-purchase information with increased availability of healthy food choices. Other categories, which included combinations of promotion, point-of-purchase information, availability and price, had insufficient evidence to suggest effectiveness ${ }^{(17)}$.

The current study aimed to contribute to the growing literature on community-based restaurant interventions. The present paper describes the implementation and results of a community-wide intervention aimed at improving the rural restaurant food environment. All restaurants in the community were provided a basic level of intervention and a subset of restaurants that chose to participate in the formal restaurant programme received a more intensive level of intervention. Results are compared by restaurant type and level of programme participation.

\section{Methods}

\section{Context}

The restaurant programme described here is one intervention component of the Heart of New Ulm (HONU)
Project. Begun in 2009, HONU is a population-based prevention project aimed at reducing myocardial infarctions and CVD risk factors in the rural community of New Ulm, Minnesota, USA ${ }^{(33-36)}$. New Ulm is located about $160 \mathrm{~km}$ (100 miles) south-west of the Minneapolis/St. Paul metropolitan area. HONU interventions are focused primarily in the 56073 zip code which has a population of 13290 adult residents (2010 Census) ${ }^{(37)}$. HONU is a collaborative partnership of Allina Health, the Minneapolis Heart Institute Foundation and the community of New Ulm.

A baseline community assessment identified obesity, metabolic syndrome, and low fruit and vegetable intake to be among key health risks to be addressed by HONU interventions ${ }^{(35)}$. HONU interventions were developed to address all levels of the social-ecological model (i.e. individual, environment, policy) ${ }^{(38)}$. Interventions are delivered through health-care, worksite and community settings. Further details about the HONU interventions have been described elsewhere ${ }^{(39)}$.

As part of the community interventions, HONU undertook several initiatives focused on improving the food environment through work with restaurants, grocery stores, convenience stores and farmers' markets. At the same time, HONU worked on increasing consumer demand for healthier foods. To help identify opportunities to address in the food environment, as well as to establish baseline practices, HONU conducted a comprehensive nutrition assessment of restaurants, grocery stores and convenience stores in this rural community ${ }^{(40)}$. Results of the baseline restaurant assessment were used to develop the restaurant programme described in more detail below. Other food environment initiatives included a pilot project with convenience stores to promote healthful snack and beverage choices, and a programme focused on increasing both demand from consumers for farmers' market and CSA (community-supported agriculture) produce as well as to increase farmer participation and operating hours of farmers' markets. Consumer-related interventions focused on food included a public-access cable television cooking show, demonstrations at grocery stores and farmers' markets, and a large-scale social marketing campaign. The 8-month social marketing campaign focused on encouraging consumers to make healthier lower-energy choices such as increasing fruits and vegetables, healthier beverages, healthier snacks, whole grains, as well as reducing fat. This social marketing campaign ran during the implementation time of the restaurant programme described here with intentional overlap. The social marketing campaign was designed to promote some of the same healthier practices to community residents that were also promoted in the restaurant programme (e.g. increased fruit and vegetable consumption, reduced portions, lower-calorie beverages) with a goal of educating consumers and increasing demand for the healthier menu selections. 


\section{Measurement and data collection}

HONU assessed restaurant practices using the Nutrition Environment Measures Survey for Restaurants (NEMS-R) ${ }^{(41)}$. The NEMS-R was created to assess dietary factors in the restaurant food environment related to risk of major chronic diseases such as obesity, diabetes and CVD. The instrument assesses the 'relative healthfulness' of foods and beverages available on main and children's menus as well as factors that might support or challenge healthier eating. The tool consists of a menu review, a restaurant observational visit and questions of restaurant staff, as needed. The instrument assesses the availability of foods meeting certain criteria: fruit without added sugar, non-fried vegetables without sauce or toppings, baked chips, wholegrain bread, and beverages with lower energy or fat (diet soda, 100\% fruit juice, $1 \%$ or non-fat milk). The instrument also measures if entrées and salads meet specific nutrition standards to identify healthful meals. In addition, the instrument includes measures of healthful eating barriers and facilitators and measures of pricing and promotions of healthier or less healthful foods ${ }^{(41)}$

Prior to conducting the NEMS-R, the HONU team received training from the NEMS development team in 2009. The two-day training included classroom sessions and practice in restaurant settings. A database was developed in Microsoft ${ }^{\circledR}$ Access 2010 to duplicate the NEMS-R instrument, with structured data entry forms and reports using scoring algorithms. The NEMS-R data were entered directly into the database using a laptop at each restaurant.

While the entire NEMS-R was conducted, the HONU team focused on sixteen healthier practices (HP; shown in Fig. 1). These items were identified as those most feasible for restaurants to implement without having to undertake a large-scale menu revision. Additionally, these practices incorporated nutrition goals identified in the baseline community needs assessment conducted by $\mathrm{HONU}^{(35)}$, such as increasing fruit and vegetable consumption and decreasing portion size.

The focus on sixteen HP measures enabled HONU to provide restaurants with feedback on their assessment results in a focused format and with a direct link to the restaurant programme activities. HP were used to rank restaurants into levels of Bronze, Silver, Gold or no level (Fig. 1). A restaurant achieved Bronze if its assessment indicated it was doing all six practices in the Bronze category (excluding any practices not applicable to that restaurant). The Silver level was achieved if a restaurant was doing all six practices in the Bronze category and also doing the additional nine items in the Silver category. To achieve a Gold level, a restaurant must offer all the applicable HP in the Bronze and Silver categories and must also have worked with a HONU dietitian to have nutritional analysis done on recipes and established at least one meal that met the criteria approving the meal by the HONU programme. To meet the HONU programme healthful meal criteria, a meal had to contain $3347 \mathrm{~kJ}$
(800 kcal) or less, $35 \%$ or less fat content, $7 \%$ or less saturated fat and $0.5 \mathrm{~g}$ or less trans-fat. Healthful meal criteria were established by NEMS-R and based on the national guidelines at the time ${ }^{(41-48)}$. The HONU team modified the NEMS-R tool for this specific measure in 2012 prior to the follow-up assessment as the national guidelines had changed ${ }^{(49,50)}$.

Prior to data collection, a letter was mailed to all restaurants in New Ulm explaining the purpose of the assessment and how to opt out of it if they did not want an assessment conducted at their restaurant. One coffee shop indicated it did not want the assessment and the decision was also made to exclude a bakery based on a very limited menu. Baseline data were collected in late 2010 and early 2011 , with the majority of assessments conducted by the project registered dietitian with assistance from a health educator. The two raters conducted cross-assessments of a few restaurants to ensure they were completing assessments comparably. Cross-assessments were done to identify any differences and further standardize scoring methods. Follow-up NEMS-R data were collected between July and December 2013 by the two registered dietitians and each of them cross-assessing eleven restaurants. The use of these data was determined to be exempt by the Allina Health Institutional Review Board.

\section{Restaurant programme intervention}

The overarching goal of the HONU restaurant programme was to partner with restaurants to increase the availability, identification and promotion of healthier food and beverage options at community restaurants, making it easier for customers to make healthier choices while eating out. The HONU restaurant programme was initiated by providing each restaurant in the community a personalized baseline assessment report documenting its status on each of the sixteen HP. The report also indicated the level the restaurant had attained, if any, at the baseline assessment (Fig. 1) and identified practice(s) the restaurant would need to implement to achieve the next level. Reports were mailed to each restaurant along with an invitation to participate in the HONU restaurant programme and to come to an initial kick-off and training event. Only four (13\%) of the eligible restaurant representatives were able to attend the training event. The HONU dietitian called all restaurants to identify a point of contact, encourage programme participation and answer questions. She met one-on-one with interested restaurant decision makers (managers, chefs, cooks or owners) from approximately half of all restaurants in the community to review the results and discuss the restaurant programme.

Restaurants choosing to participate in the programme signed a 1-year agreement that outlined both restaurant and HONU programme responsibility. These varied by the level of participation but included the basic step of the restaurants identifying a level at which they agreed to 


\begin{tabular}{|c|c|c|}
\hline Healthy Practices for Bronze Level & Doing it now & Opportunities \\
\hline 1. One or more non-fried vegetable side dish(es) is offered daily & $\checkmark$ & \\
\hline 2. One or more half-size portion entrée(s) is available daily & $\checkmark$ & \\
\hline $\begin{array}{l}\text { 3. If a kids' menu is available, healthy sides (e.g. fresh fruit, non- } \\
\text { fried vegetable) are available in place of fries or chips AND } \\
\text { healthy beverages (e.g. fat-free milk, low-fat milk, } 100 \% \text { juice) } \\
\text { are available in place of sugar-sweetened beverages }\end{array}$ & $\checkmark$ & \\
\hline $\begin{array}{l}\text { 4. Fat-free or low-fat milk AND a low-or no-calorie beverage (e.g. } \\
\text { diet soda) are offered daily }\end{array}$ & $\checkmark$ & \\
\hline 5. If snack chips are available, baked chips are offered as a choice & N/A & N/A \\
\hline 6. Low-fat or fat-free salad dressing is available daily & $\checkmark$ & \\
\hline Healthy Practices for Silver Level & Doing it now & Opportunities \\
\hline 7. One or more no-added-sugar fruit side dish(es) is offered daily & $\checkmark$ & \\
\hline $\begin{array}{l}\text { 8. With all entrées, salad, fruit (no added sugar) and/or non-fried } \\
\text { vegetables are offered as a standard side and French fries, } \\
\text { potato chips, etc. are offered as substitutions }\end{array}$ & $\checkmark$ & \\
\hline $\begin{array}{l}\text { 9. Sandwich buns are not automatically buttered unless the } \\
\text { customer asks }\end{array}$ & & $\checkmark$ \\
\hline $\begin{array}{l}\text { 10. Spreads (e.g. mayonnaise or butter) and dressings are placed } \\
\text { on the side for all sandwiches and wraps }\end{array}$ & $\checkmark$ & \\
\hline $\begin{array}{l}\text { 11. Olive oil or trans-fat free margarine is available alongside or in } \\
\text { place of butter on the table, salad bar or serving area }\end{array}$ & & $\checkmark$ \\
\hline 12. A minimum of three half-portion entrées is available daily & $\checkmark$ & \\
\hline $\begin{array}{l}\text { 13. One or more wholegrain bread or bun option(s) is available for } \\
\text { all sandwiches, burgers and bread baskets }\end{array}$ & $\checkmark$ & \\
\hline 14. Trans-fat free/saturated fat free frying oil is used daily & & $\checkmark$ \\
\hline $\begin{array}{l}\text { 15. All healthy practices are promoted on the menu, a menu insert } \\
\text { or a table tent so that the customer can see options prior to } \\
\text { ordering }\end{array}$ & $\checkmark$ & \\
\hline Healthy Practices for Gold Level & Doing it now & Opportunities \\
\hline $\begin{array}{l}\text { 16. One or more HONU Project-approved healthy dish(es) is on } \\
\text { the menu }\end{array}$ & & $\checkmark$ \\
\hline
\end{tabular}

Fig. 1 (colour online) Sample restaurant environment assessment report for the Heart of New Ulm (HONU) Project (N/A, not applicable)

participate (Bronze, Silver, Gold). If they did not meet their identified level at baseline, they were required to add the HP for that level that had been identified as unavailable in their baseline report prior to being advertised by HONU as a participant. Restaurants also had to maintain those practices for the duration of 1 year and ensure their staff received training on the programme and HP requirements for their restaurant's level of participation. HONU programme responsibilities at the Bronze level included promoting the restaurants quarterly to residents through the local media (e.g. newspaper advertisements, billboards, cable access television and radio advertisements) and a large email distribution list, providing pointof-choice signage (table tents or menu inserts) for the restaurants to use, providing a door cling highlighting level of achievement, providing in-service staff training, and allowing the restaurant to participate in and provide healthful food samples at an annual HONU community event. Higher levels of participation (i.e. Silver and Gold) received free dietitian consultation, promotion of the restaurant at a food-sampling event, promotion of the restaurant on a HONU cooking television show on cable access, point-of-purchase and promotional materials, and coupons for the restaurant generated and paid for by the HONU programme. When restaurants indicated they had implemented HP needed to achieve the level in the contract, a dietitian would reassess to make sure these changes were reflected in the menu and operations. HONU conducted quarterly quality assurance checks on each participating restaurant to ensure programme obligations were being met. All programme contacts with restaurants and completion of activities by the programme or restaurant were documented in an Access 2010 database.

\section{Analysis}

Data analysis was done using the statistical software package PASW Statistics version 18.0. Frequencies were used to describe restaurant characteristics and results of the NEMS-R and HONU HP achieved. To compare change in practices over time within this cohort, we conducted crosstabulations with McNemar's $\chi^{2}$ tests. Cross-tabulations were also used to describe practices for restaurants participating and those not participating in the programme as well as by 
different restaurant types. The $\chi^{2}$ testing was done only on the overall achievement measure.

\section{Results}

\section{Assessment and programme participation}

A total of thirty-three restaurants were assessed at baseline, representing all community restaurants at that time. Of those, thirty-two restaurants have both a time 1 and time 2 assessment. Just over half (56\%) of community restaurants were independent and $44 \%$ were a chain or franchise (Table 1). Most were sit-down restaurants with table service (69\%), $22 \%$ were fast-food restaurants, and $9 \%$ were carry out or delivery only. Half of the restaurants had cuisine classified as 'general/American' on the assessment tool, 19\% were pizza restaurants, 9\% served primarily burgers, $9 \%$ served Mexican food and $6 \%$ served Asian food.

As indicated in Table 2, twenty-five of the thirty-two (78\%) restaurants had baseline assessment results indicating they did not offer enough HP to achieve the Bronze, Silver or Gold level. After HONU shared results with restaurants and completed recruitment, nine restaurants joined the programme initially and this grew to twelve in total $(38 \%)$ signing an agreement to participate over the course of 1 year.

Restaurants that joined the programme were more likely to be independent, with eight of twelve programme restaurants classified as independent compared with an even split of ten chain and ten independent restaurants among those that did not join the programme (Table 1). Restaurants that joined the programme were much more likely to have achieved a level at baseline and were generally more likely to offer several of the HP assessed (Table 2). While we are unable to conduct statistical tests

Table 1 Description of community restaurants and programme participation, Heart of New Ulm (HONU) Project, Minnesota, USA

\begin{tabular}{|c|c|c|c|c|c|c|}
\hline & \multicolumn{2}{|c|}{$\begin{array}{l}\text { Total } \\
(n \text { 32) }\end{array}$} & \multicolumn{2}{|c|}{$\begin{array}{l}\text { Joined } \\
\text { programme } \\
(n 12)\end{array}$} & \multicolumn{2}{|c|}{$\begin{array}{l}\text { Did not join } \\
\text { programme } \\
\quad(n 20)\end{array}$} \\
\hline & $n$ & $\%$ & $n$ & $\%$ & $n$ & $\%$ \\
\hline \multicolumn{7}{|l|}{ Ownership } \\
\hline Chain/franchise & 14 & 44 & 4 & 33 & 10 & 50 \\
\hline Independent & 18 & 56 & 8 & 66 & 10 & 50 \\
\hline \multicolumn{7}{|l|}{ Type } \\
\hline Carry out/delivery only & 3 & 9 & 0 & 0 & 3 & 15 \\
\hline Fast food & 72 & 22 & 3 & 25 & 4 & 20 \\
\hline Sit down & 22 & 69 & 9 & 75 & 13 & 65 \\
\hline \multicolumn{7}{|l|}{ Cuisine } \\
\hline General/American & 16 & 50 & 9 & 75 & 7 & 35 \\
\hline Pizza & 6 & 19 & 0 & 0 & 6 & 30 \\
\hline Asian & 2 & 6 & 0 & 0 & 2 & 10 \\
\hline Mexican & 3 & 9 & 0 & 0 & 3 & 15 \\
\hline Burgers & 3 & 9 & 2 & 17 & 1 & 5 \\
\hline Chicken & 1 & 3 & 0 & 0 & 1 & 5 \\
\hline Sandwiches & 1 & 3 & 1 & 8 & 0 & 0 \\
\hline
\end{tabular}

by cuisine type due to small numbers, participation did seem to vary based on cuisine. Specifically, all the pizza restaurants $(n 6)$ did not join, neither did either of the Chinese $(n$ 2) or the Mexican restaurants ( $n$ 3; Table 1 ). This may be related to the type of restaurant ownership: chain restaurants were less likely to join, and five of the six pizza restaurants and two of the three Mexican restaurants were chains. However, both Chinese restaurants were independent.

\section{Changes in practices}

During the first 3 years of programme implementation, the number of restaurants in the community that achieved a level in the HONU restaurant programme increased from seven $(21.9 \%)$ to twelve $(37.5 \%$; Table 2$)$. Of all HP assessed, five demonstrated significant increases in adoption by restaurants: non-fried vegetable; half-size portions; healthful side and drink options on the children's menu; having a minimum of three half-portion entrées available; and having menu items meeting the HONU nutrition criteria. Several other HP showed a non-significant increase in adoption by restaurants. Two Bronze HP, low-fat/ low-calorie beverages and low-fat/fat-free salad dressing, did not improve because two restaurants each discontinued one of these practices.

Restaurants participating in the programme were significantly more likely to have achieved a level than those not participating $(91.7 v .5 .0 \%, P<0.001$; Table 3). One restaurant that joined the programme was not achieving any level at the follow-up assessment. This restaurant had joined the programme at a Bronze level and had added HP to achieve that level after joining the programme, but then chose to discontinue offering baked chips before the 1 -year contract period was over. At the end of the project, only one non-participating restaurant had made sufficient changes to reach a level, while six programme restaurants went from either no level to a level, or increased level. While only one non-participating restaurant achieved a level, several HP were adopted and therefore showed improvement among this group of restaurants. Specifically, offering a non-fried vegetable, offering half-size portions, offering a fruit with no sugar added, not buttering sandwich buns automatically, offering a side other than fries with entrées as the default and spreads on the side all increased among non-participating restaurants.

Increased adoption of HP occurred both among independent and chain restaurants for the most commonly improved HP (Table 3). However, independent restaurants were more likely to report offering many of the specific HP at follow-up than the chain restaurants. This is true for offering half-portion size entrées, baked chips, fruit with no added sugar, not buttering sandwich buns, spreads on the side, olive oil/trans-fat free spread alternatives, offering three half-portion size entrées, wholegrain bread and trans-fat free frying oil. While chain restaurants were more 
Table 2 Prevalence of healthy practices at baseline and follow-up for community restaurants $(n$ 32), Heart of New Ulm (HONU) Project, Minnesota, USA

\begin{tabular}{|c|c|c|c|c|c|}
\hline \multirow[b]{2}{*}{ Healthy practices offered daily } & \multicolumn{2}{|c|}{ Baseline (2010) } & \multicolumn{2}{|c|}{ Follow-up (2013) } & \multirow[b]{2}{*}{$P$ value } \\
\hline & $n$ & $\%$ & $n$ & $\%$ & \\
\hline \multicolumn{6}{|l|}{ Bronze } \\
\hline One or more non-fried vegetable side dish(es) & 20 & 62.5 & 27 & 84.4 & 0.016 \\
\hline One or more half-size portion entrée(s) & 10 & $31 \cdot 3$ & 23 & 71.9 & $<0.001$ \\
\hline Kids' menu (if available) includes healthy side AND beverage option(s) & 7 & 21.9 & 13 & $40 \cdot 6$ & 0.032 \\
\hline Fat-free or low-fat milk AND a low- or no-calorie beverage & 29 & $90 \cdot 6$ & 28 & $87 \cdot 5$ & 0.999 \\
\hline If snack chips are available, baked chips are offered as a choice & 3 & $9 \cdot 7$ & 7 & $22 \cdot 6$ & 0.129 \\
\hline Low-fat or fat-free salad dressing & 25 & $78 \cdot 1$ & 24 & $75 \cdot 0$ & 0.607 \\
\hline \multicolumn{6}{|l|}{ Silver } \\
\hline One or more fruit side dish(es) with no added sugar & 13 & $40 \cdot 6$ & 17 & $53 \cdot 1$ & 0.289 \\
\hline Salad, fruit or non-fried vegetables are offered as the standard side & 7 & $22 \cdot 6$ & 14 & $45 \cdot 2$ & 0.065 \\
\hline Sandwich buns are not automatically buttered & 9 & $28 \cdot 1$ & 16 & $50 \cdot 0$ & 0.092 \\
\hline Spreads and dressings are placed on the side for all sandwiches & 8 & $25 \cdot 0$ & 11 & 34.4 & 0.615 \\
\hline Olive oil or trans-fat free margarine is available & 26 & $81 \cdot 3$ & 29 & $90 \cdot 6$ & 0.311 \\
\hline A minimum of three half-portion entrées & 7 & 21.9 & 16 & $50 \cdot 0$ & 0.022 \\
\hline One or more wholegrain bread or bun option(s) & 8 & $25 \cdot 0$ & 12 & 37.5 & 0.219 \\
\hline Trans-fat free/saturated fat free frying oil is used & 29 & 93.5 & 29 & 93.5 & NA \\
\hline Healthy practices are promoted on the menu or a table tent & 7 & $22 \cdot 6$ & 6 & $19 \cdot 4$ & 0.999 \\
\hline Gold & & & & & \\
\hline One or more HONU Project-approved healthy dish(es) is on menu & 2 & 6.5 & 10 & $32 \cdot 3$ & 0.008 \\
\hline \multirow{2}{*}{\multicolumn{6}{|c|}{ HONU Healthy Practices level achievement }} \\
\hline & & & & & \\
\hline No level achieved & 25 & $78 \cdot 1$ & 20 & 62.5 & 0.199 \\
\hline Bronze & 5 & $16 \cdot 1$ & 8 & $25 \cdot 0$ & \\
\hline Silver & 1 & $3 \cdot 1$ & 1 & 3.1 & \\
\hline Gold & 1 & $3 \cdot 1$ & 3 & $9 \cdot 4$ & \\
\hline Any level achieved (\% yes) & 7 & 21.9 & 12 & 37.5 & 0.063 \\
\hline
\end{tabular}

NA, not applicable.

likely to meet a programme level at baseline (29\%) compared with independent restaurants (17\%), the reverse was true at follow-up. At follow-up, there was no change in the proportion of chain restaurants meeting a level (29\%) while the proportion of independent restaurants meeting a level had more than doubled (44\%).

\section{Discussion}

The development and testing of interventions to increase access, availability, identification and promotion of healthier foods in the restaurant environment is a public health priority $^{(51)}$. The present study demonstrates the development, implementation and success of an initiative to improve healthful food availability and promotion in all restaurants in a single community. This programme is innovative because it uses a validated assessment tool, reaches all restaurants with educational information on how to increase availability of healthful foods at their restaurant, and offers a comprehensive programme to improve healthful food availability, identification and promotion that includes a ranking system easily used to market to consumers. Key outcomes of the study included: (i) successful recruitment of over one-third of community restaurants into a comprehensive programme; (ii) improvements in specific $\mathrm{HP}$ in the restaurant food environment occurring among both participating and non-participating restaurants; and (iii) a finding that independently owned restaurants were more likely to make changes than chain restaurants.

Not only did this initiative reach all restaurants with a basic level of education on the opportunities to make health improvements in their offerings, but we were able to recruit over one-third of all restaurants to participate in a more intensive multi-year partnership to improve their HP. Additionally, there was no attrition by restaurants during the programme period. Prior studies describing communitywide interventions are rare, making it hard to compare participant and food environment changes over time in our study with those of other community-wide studies. One study recruited restaurants in a community but assessed change only within participants and not across the entire community ${ }^{(52)}$. Our level of restaurant participation (38\%) compares favourably with the $12 \%$ of restaurants in a more urban study ${ }^{(52)}$. A Canadian study in two cities recruiting restaurants with table service only (excluding fast food) reported higher engagement, $56 \%$ and $68 \%$ in each of the cities $^{(53)}$. In that programme, restaurants were not required to have HP available on the menu as with our study, but rather were required to make certain HP available if consumers requested them.

While restaurant engagement levels were promising in our study, there was a noted pattern in the lack of participation in the comprehensive programme by restaurants with specific types of cuisine (e.g. pizza, Mexican, Chinese); however, this may have also been related to 
Table 3 Prevalence of healthy practices at baseline (2010) and follow-up (2013) for community restaurants $(n$ 32), stratified by programme participation and restaurant type, Heart of New UIm (HONU) Project, Minnesota, USA

\begin{tabular}{|c|c|c|c|c|c|c|c|c|c|c|c|c|c|c|c|c|}
\hline & \multicolumn{4}{|c|}{$\begin{array}{l}\text { Not in programme } \\
(n 20)\end{array}$} & \multicolumn{4}{|c|}{ In programme $(n 12)$} & \multicolumn{4}{|c|}{ Independent $(n$ 18) } & \multicolumn{4}{|c|}{ Chain $(n 14)$} \\
\hline & \multicolumn{2}{|c|}{ Baseline } & \multicolumn{2}{|c|}{$\begin{array}{l}\text { Follow- } \\
\text { up }\end{array}$} & \multicolumn{2}{|c|}{ Baseline } & \multicolumn{2}{|c|}{$\begin{array}{l}\text { Follow- } \\
\text { up }\end{array}$} & \multicolumn{2}{|c|}{ Baseline } & \multicolumn{2}{|c|}{$\begin{array}{l}\text { Follow- } \\
\text { up }\end{array}$} & \multicolumn{2}{|c|}{ Baseline } & \multicolumn{2}{|c|}{$\begin{array}{l}\text { Follow- } \\
\text { up }\end{array}$} \\
\hline & $n$ & $\%$ & $n$ & $\%$ & $n$ & $\%$ & $n$ & $\%$ & $n$ & $\%$ & $n$ & $\%$ & $n$ & $\%$ & $n$ & $\%$ \\
\hline \multicolumn{17}{|l|}{ Bronze } \\
\hline One or more non-fried vegetable side dish(es) & 8 & $40 \cdot 0$ & 15 & $75 \cdot 0$ & 12 & $100 \cdot 0$ & 12 & $100 \cdot 0$ & 11 & $61 \cdot 1$ & 15 & 83.3 & 9 & 64.3 & 12 & 85.7 \\
\hline One or more half-size portion entrée(s) & 2 & $10 \cdot 0$ & 11 & $55 \cdot 0$ & 8 & $66 \cdot 7$ & 12 & $100 \cdot 0$ & 5 & $27 \cdot 8$ & 14 & $77 \cdot 8$ & 5 & $35 \cdot 7$ & 9 & $64 \cdot 3$ \\
\hline $\begin{array}{l}\text { Kids' menu includes healthy side AND beverage } \\
\text { options }\end{array}$ & 3 & $15 \cdot 0$ & 3 & $15 \cdot 0$ & 4 & $33 \cdot 3$ & 10 & $83 \cdot 3$ & 1 & $5 \cdot 6$ & 6 & $33 \cdot 3$ & 6 & 42.9 & 7 & $50 \cdot 0$ \\
\hline $\begin{array}{l}\text { Fat-free or low-fat milk AND a low- or no-calorie } \\
\text { beverage }\end{array}$ & 17 & $85 \cdot 0$ & 16 & $80 \cdot 0$ & 12 & $100 \cdot 0$ & 12 & $100 \cdot 0$ & 17 & 94.4 & 17 & 94.4 & 12 & $85 \cdot 7$ & 11 & $78 \cdot 6$ \\
\hline If snack chips are available, baked chips are offered & 2 & $10 \cdot 0$ & 2 & $10 \cdot 0$ & 1 & 8.3 & 5 & 41.7 & 1 & $5 \cdot 6$ & 4 & $22 \cdot 2$ & 2 & $15 \cdot 4$ & 3 & $23 \cdot 1$ \\
\hline Low-fat or fat-free salad dressing & 13 & $65 \cdot 0$ & 12 & $60 \cdot 0$ & 12 & $100 \cdot 0$ & 12 & $100 \cdot 0$ & 14 & $77 \cdot 8$ & 13 & $72 \cdot 2$ & 11 & 78.6 & 11 & 78.6 \\
\hline \multicolumn{17}{|l|}{ Silver } \\
\hline One or more fruit side dish(es) with no added sugar & 6 & $30 \cdot 0$ & 9 & $45 \cdot 0$ & 7 & $58 \cdot 3$ & 8 & $66 \cdot 7$ & 6 & 33.3 & 8 & 62.5 & 7 & $50 \cdot 0$ & 9 & $64 \cdot 3$ \\
\hline $\begin{array}{l}\text { Salad, fruit or non-fried vegetables are offered as the } \\
\text { standard side }\end{array}$ & 5 & $25 \cdot 0$ & 7 & 35.0 & 2 & $16 \cdot 6$ & 7 & $58 \cdot 3$ & 6 & $35 \cdot 3$ & 8 & 44.4 & 1 & $7 \cdot 1$ & 6 & $42 \cdot 9$ \\
\hline Sandwich buns are not automatically buttered & 4 & $20 \cdot 0$ & 8 & $40 \cdot 0$ & 5 & 41.7 & 8 & $66 \cdot 7$ & 5 & $27 \cdot 8$ & 11 & $61 \cdot 1$ & 4 & 28.6 & 5 & 35.7 \\
\hline $\begin{array}{l}\text { Spreads and dressings are placed on the side for all } \\
\text { sandwiches }\end{array}$ & 3 & $15 \cdot 0$ & 1 & $25 \cdot 0$ & 5 & $41 \cdot 7$ & 7 & $58 \cdot 3$ & 5 & $27 \cdot 8$ & 9 & $50 \cdot 0$ & 3 & 21.4 & 2 & $14 \cdot 3$ \\
\hline Olive oil or trans-fat free margarine is available & 15 & $75 \cdot 0$ & 17 & $85 \cdot 0$ & 11 & $91 \cdot 7$ & 12 & $100 \cdot 0$ & 17 & 94.4 & 17 & 94.4 & 9 & $64 \cdot 3$ & 12 & $85 \cdot 7$ \\
\hline A minimum of three half-portion entrées & 3 & $15 \cdot 0$ & 5 & $25 \cdot 0$ & 4 & 33.3 & 11 & $91 \cdot 7$ & 2 & $11 \cdot 1$ & 10 & 55.6 & 5 & 35.7 & 6 & 42.9 \\
\hline One or more wholegrain bread or bun option(s) & 3 & $15 \cdot 0$ & 3 & $15 \cdot 0$ & 5 & $41 \cdot 7$ & 9 & $75 \cdot 0$ & 4 & $22 \cdot 2$ & 9 & $50 \cdot 0$ & 4 & $28 \cdot 6$ & 3 & 21.4 \\
\hline Trans-fat free/saturated fat free frying oil is used & 18 & $90 \cdot 0$ & 18 & $90 \cdot 0$ & 12 & $100 \cdot 0$ & 12 & $100 \cdot 0$ & 18 & $100 \cdot 0$ & 18 & $100 \cdot 0$ & 12 & 85.7 & 12 & $85 \cdot 7$ \\
\hline $\begin{array}{l}\text { Healthy practices are promoted on the menu or a } \\
\text { table tent }\end{array}$ & 3 & $15 \cdot 0$ & 1 & $5 \cdot 0$ & 4 & 33.3 & 5 & $41 \cdot 7$ & 3 & $16 \cdot 7$ & 4 & $22 \cdot 2$ & 4 & $28 \cdot 6$ & 2 & $14 \cdot 3$ \\
\hline \multicolumn{17}{|l|}{ Gold } \\
\hline $\begin{array}{l}\text { One or more HONU Project-approved healthy } \\
\text { dish(es) is on menu }\end{array}$ & 1 & $5 \cdot 0$ & 4 & 20 & 1 & $8 \cdot 3$ & 6 & $50 \cdot 0$ & 1 & $5 \cdot 6$ & 3 & $16 \cdot 7$ & 1 & $7 \cdot 1$ & 7 & $50 \cdot 0$ \\
\hline \multicolumn{17}{|l|}{ HONU Healthy Practices level achievement } \\
\hline Any level (Gold, Silver, Bronze) achieved & 0 & 0.0 & 1 & $5 \cdot 0$ & 7 & $58 \cdot 3$ & 11 & 91.7 & 3 & $16 \cdot 7$ & 8 & 44.4 & 4 & $28 \cdot 6$ & 4 & $28 \cdot 6$ \\
\hline
\end{tabular}

several of these being chain restaurants. This is also potentially a result of the limitations of our identified HP for some specific cuisines. For example, buffet-style and pizza restaurants would not be able to meet portion-size HP and restaurants serving chips and salsa may not be willing to make the switch to baked chips. Ours is not the first study to document challenges for participation by cuisine type. A prior community-wide restaurant initiative chose to give pizza restaurants low priority for recruitment given that changes targeted by the programme were less likely to be made in pizza restaurants, and they modified programme criteria to accommodate buffet-style restaurants ${ }^{(52)}$.

Differences between independent and chain restaurants was another key finding in our study. While chain restaurants were more likely to have sufficient HP in place to meet one of our HP levels at baseline, independent restaurants were more likely to both join our programme and to make changes. In fact, at the end of the follow-up period, there was no change in the proportion of chain restaurants meeting a level while the proportion of independent restaurants meeting a level had more than doubled. In 2010 as part of the Affordable Care Act, Congress passed a national law requiring chain restaurants with twenty or more outlets to list energy and other nutrition information on menus and menu boards. Although the Food and Drug Administration did not require final compliance during the time of the present study, many restaurants began making nutrition information available to customers in the time prior to our baseline assessment. This attention to documenting nutrition practices by chain restaurants may explain the higher HP achievement in chain restaurants at baseline. Differential change in HP or other intervention outcomes by chain and independent restaurants in a community-wide initiative has not been documented before. However, another study excluded chain restaurants as decisions related to participation and menu change were corporate decisions ${ }^{(52)}$. Limited changes among chain restaurants may reflect their limited authority to make local decisions about joining a programme or making menu changes. A study designed to measure the energy content of foods from independent and small-chain restaurants that do not provide nutritional information also found that meals measured through bomb calorimetry had two times the energy required for weight maintenance and more energy than the most popular meal choices from the largest national chain restaurant that provided nutrition information ${ }^{(54)}$. These findings and those from our study suggest that the greatest opportunity to influence change in the restaurant environment of a rural community may be with independent restaurants. 
Our programme used a set of HP rather than focusing on modification of current menu items for practical implementation across a community. This approach was enabled by the use of a validated nutrition environment assessment tool $^{(41)}$. This model worked well for ease of comparison across the community and we did see marked improvements in key HP. Because all restaurants in New Ulm were given reports about how they could improve offerings and achieve levels, some implemented changes even though they did not join the programme. Often these changes were ones that would significantly increase the availability of healthful offerings (i.e. half-portions, non-fried vegetables and fruit without sugar) in a community where obesity and low fruit and vegetable consumption were identified as problems ${ }^{(35)}$. Increases in the number of restaurants that offer fruits and vegetables and smaller portions represent a significant improvement in the food environment of this rural community. Our ability to compare these outcomes with previous restaurant environment initiatives is challenged by the varied intervention strategies of the present work.

\section{Limitations}

One limitation of the present study is that it may not be generalizable to other communities. Additionally, because the study was conducted in an applied setting rather than being a randomized trial, we cannot conclusively state that all improvements seen were due to the intervention exclusively. However, the documentation of changes in the entire community and the ability to compare participants with non-participants provide supporting evidence for the effectiveness of the intervention given the increased likelihood of changes among participating restaurants. A limitation and simultaneously a strength of the intervention may be the set of HP employed. This strategy was based on the innovative use of a validated instrument that could be used to assess, document changes and educate sites on improvement opportunities. However, the specific set of HP may have been limiting for some sites. As with other studies focused on changing the environment, our study was unable to measure consumer impact and we recognize the need for future studies to assess if consumer changes are associated with changes in HP.

\section{Conclusion}

The present study documents a community-wide programme aimed at improving the rural restaurant environment with a relatively simple-to-implement intervention. The programme recruited just over one-third of restaurants in the community to join. Overall, the HP improved among restaurants both in the programme and not in the programme, but those in the programme were more likely to meet all criteria necessary to achieve a level. Independent restaurants were more likely to both join the programme and adopt HP compared with chain restaurants.

\section{Acknowledgements}

Financial support: This work was funded by a grant from the UnitedHealth Group and through general funding for the Heart of New Ulm Project provided by Allina Health. The funders had no role in the design, analysis or writing of this article. Conflict of interest: A.C.S., B.M. and A.S. were employees of Allina Health, one of the funding organizations, at the time of this study. However, their salaries or employment were in no way affected by the study findings. Authorship: R.L.: conceptual development of the intervention, grant proposal development for funding, oversaw the intervention work, contributed to the design of the study, oversaw data cleaning, contributed to all sections of the manuscript, final editing. A.C.S.: led the evaluation design, oversaw data cleaning, oversaw data analysis, wrote sections of the paper, conducted final editing. B.M.: conducted literature reviews, contributed to multiple sections of the manuscript. R.F.P.: oversaw data collection for the project, conceptual development of the intervention, oversaw some intervention components, contributed to design of study, manuscript editing. A.S.: worked on data management and cleaning, conducted data analysis, developed tables, wrote the analysis section of the manuscript. J.L.B.: conceptual development of the intervention, grant proposal development for funding, oversight of programme, contributed to design of study, manuscript editing. Ethics of human subject participation: Not applicable because this study did not include human subjects.

\section{References}

1. Ogden CL, Carroll MD, Kit BK et al. (2014) Prevalence of childhood and adult obesity in the United States, 2011-2012. JAMA 311, 806-814.

2. Centers for Disease Control and Prevention (2014) Health, United States: Table 59. http://www.cdc.gov/nchs/data/ hus/hus14.pdf \#059 (accessed November 2015).

3. Fleischhacker SE, Evenson KR, Rodriguez DA et al. (2011) A systematic review of fast food access studies. Obes Rev 12, e460-e471.

4. Currie J, Della Vigna S, Moretti E et al. (2010) The effect of fast food restaurants on obesity and weight gain. Am Econ J Econ Policy 2, 34-36.

5. Kant AK \& Graubard BI (2004) Eating out in America, 1987-2000: trends and nutritional correlates. Prev Med 38, 243-249.

6. Bezerra IN, Curioni C \& Sichieri R (2012) Association between eating out of home and body weight. Nutr Rev 70, 65-79.

7. Todd JE, Mancino L \& Lin BH (2010) The Impact of Food Away from Home on Adult Diet Quality. Economic Research Report no. ERR-90. Washington, DC: US Department of Agriculture, Economic Research Service.

8. Young LR \& Nestle M (2002) The contribution of expanding portion sizes to the US obesity epidemic. Am J Public Health 92, 246-249. 
9. Piernas C \& Popkin BM (2011) Food portion patterns and trends among US children and the relationship to total eating occasion size, 1977-2006. J Nutr 141, 1159-1164.

10. Lin BH, Frazao E \& Guthrie J (1999) Away-From-Home Foods Increasingly Important to Quality of American Diet. Agricultural Information Bulletin no. AIB-749. Washington, DC: US Department of Agriculture Economic Research Service, Food and Drug Administration and US Department of Health and Human Services.

11. Barnett E \& Halverson J (2000) Disparities in premature coronary heart disease mortality by region and urbanicity among black and white adults ages 35-64, 1985-1995. Public Health Rep 115, 52-64.

12. O'Connor A \& Wellenius G (2012) Rural-urban disparities in the prevalence of diabetes and coronary heart disease. Public Health 126, 813-820.

13. Morton LW \& Blanchard TC (2007) Starved for access: life in rural America's food deserts. Rural Realities 1, issue 4; available at https://www.iatp.org/files/258_2_98043.pdf

14. Bustillos B, Sharkey JR, Anding J et al. (2009) Availability of more healthful food alternatives in traditional, convenience, and nontraditional types of food stores in two rural Texas counties. J Am Diet Assoc 109, 883-889.

15. Kegler MC, Swan DW, Alcantara I et al. (2013) The influence of rural home and neighborhood environments on healthy eating, physical activity, and weight. Prev Sci 15, 1-11.

16. US Census Bureau (2016) New Census Data Show Differences Between Urban and Rural Populations. http:// www.census.gov/newsroom/press-releases/2016/cb16-210.html (accessed September 2017).

17. Valdivia Espino JN, Guerrero N, Rhoads N et al. (2015) Community-based restaurant interventions to promote healthy eating: a systematic review. Prev Chronic Dis 12, E78.

18. Sharkey JR, Johnson CM, Dean WR et al. (2011) Association between proximity to and coverage of traditional fast-food restaurants and non-traditional fast-food outlets and fastfood consumption among rural adults. Int J Health Geogr 10, 37.

19. Creel JS, Sharkey JR, McIntosh A et al. (2008) Availability of healthier options in traditional and nontraditional rural fastfood outlets. BMC Public Health 8, 395.

20. Story M, Kaphingst KM, Robinson-O'Brien R et al. (2008) Creating healthy food and eating environments: policy and environmental approaches. Annu Rev Public Health 29, 253-272.

21. McKinnon RA, Reedy J, Morrissette MA et al. (2009) Measures of the food environment: a compilation of the literature, 1990-2007. Am J Prev Med 36, Suppl. 4, S124-S133.

22. McKinnon RA, Reedy J, Handy SL et al. (2009) Measuring the food and physical activity environments: shaping the research agenda. Am J Prev Med 36, Suppl. 4, S81-S85.

23. Krieger JW, Chan NL, Saelens BE et al. (2013) Menu labeling regulations and calories purchased at chain restaurants. Am J Prev Med 44, 595-604.

24. Long MW, Tobias DK, Cradock AL et al. (2015) Systematic review and meta-analysis of the impact of restaurant menu calorie labeling. Am J Public Health 105, e11-e24.

25. Nordstrom J \& Thunstrom L (2015) The impact of price reductions on individuals' choice of healthy meals away from home. Appetite 89, 103-111.

26. Nothwehr FK, Snetselaar L, Dawson J et al. (2013) Promoting healthy choices in non-chain restaurants: effects of a simple cue to customers. Health Promot Pract 14, 132-138.

27. Lesser LI, Hunnes DE, Reyes P et al. (2012) Assessment of food offerings and marketing strategies in the food-service venues at California Children's Hospitals. Acad Pediatr 12, 62-67.

28. Block JP, Condon SK, Kleinman K et al. (2013) Consumers' estimation of calorie content at fast food restaurants: cross sectional observational study. BMJ 346, f2907.
29. Martinez-Donate AP, Riggall AJ, Meinen AM et al. (2015) Evaluation of a pilot healthy eating intervention in restaurants and food stores of a rural community: a randomized community trial. BMC Public Health 15, 136.

30. James A, Adams-Huet B \& Shah M (2015) Menu labels displaying the kilocalorie content or the exercise equivalent: effects on energy ordered and consumed in young adults. Am J Health Promot 26, 294-302.

31. Guthrie JF, Lin B-H \& Frazao E (2002) Role of food prepared away from home in the American diet, 1977-78 versus 1994-96: changes and consequences. J Nutr Educ Behav 34, 140-150.

32. Sosa ET, Biediger-Friedman L \& Banda M (2014) Associations between a voluntary restaurant menu designation initiative and patron purchasing behavior. Health Promot Pract 15, 281-287.

33. Boucher JL, Pereira RF, Graham KJ et al. (2008) The Heart of New Ulm: a vision for the future. J Cardiovasc Transl Res 1, 310-316.

34. VanWormer JJ (2010) Methods of using electronic health records for population-level surveillance of coronary heart disease risk in the Heart of New Ulm Project. Diabetes Spectr 23, 161-165.

35. VanWormer JJ, Johnson PJ, Pereira RF et al. (2012) The Heart of New Ulm Project: using community-based cardiometabolic risk factor screenings in a rural population health improvement initiative. Popul Health Manag 15, 135-143.

36. Sillah A, Sidebottom AC, Boucher JL et al. (2014) Program participation and blood pressure improvement in the Heart of New Ulm Project, Minnesota, 2009-2011. Prev Chronic Dis 11, E48.

37. Census Bureau US (2010) State \& County Quick Facts: New Ulm (city), Minnesota. http://www.quickfacts.census. gov/qfd/states/27/2746042.html (accessed November 2015).

38. McLeroy KR, Bibeau D, Steckler A et al. (1988) An ecological perspective on health promotion programs. Health Educ Q 15, 351-377.

39. Sidebottom AC, Sillah A, Miedema MD et al. (2016) Changes in cardiovascular risk factors after 5 years of implementation of a population-based program to reduce cardiovascular disease: the Heart of New Ulm Project. Am Heart J 175, 66-76.

40. Pereira RF, Sidebottom AC, Boucher JL et al. (2014) Assessing the food environment of a rural community: baseline findings from the Heart of New Ulm Project, Minnesota, 2010-2011. Prev Chronic Dis 11, E36.

41. Saelens BE, Glanz K, Sallis JF et al. (2007) Nutrition Environment Measures Study in restaurants (NEMS-R): development and evaluation. Am J Prev Med 32, 273-281.

42. US Department of Health and Human Services \& US Department of Agriculture (2005) Dietary Guidelines for Americans 2005, 6th ed. Washington, DC: US Government Printing Office.

43. US Food and Drug Administration (1994) A Food Labeling Guide: Reference Values for Food Labeling. College Park, MD: Center for Food Safety and Applied Nutrition, FDA.

44. Institute of Medicine (2002) Dietary Reference Intakes for Energy, Carbohydrate, Fiber, Fat, Fatty Acids, Cholesterol, Protein, and Amino Acids. Washington, DC: National Academies Press.

45. Hurley J \& Liebman B (2004) Kids' Cuisine: 'What would You Like with Your Fries?' Washington, DC: Center for Science in the Public Interest.

46. Warshaw H (2002) Guide to Healthy Restaurant Eating. Alexandria, VA: American Diabetes Association.

47. Jacobson MF \& Hurley J (2002) Restaurant Confidential. New York: Workman Publishing.

48. Cassady D, Housemann R \& Dagher C (2004) Measuring cues for healthy choices on restaurant menus: development and testing of a measurement instrument. Am J Health Promot 18, 444-449. 
49. US Department of Agriculture \& US Department of Health and Human Services (2010) Dietary Guidelines for Americans 2010, 7th ed. Washington, DC: US Government Printing Office.

50. American Heart Association Nutrition Committee, Lichtenstein AH, Appel LJ et al. (2006) Diet and lifestyle recommendations revision 2006: a scientific statement from the American Heart Association Nutrition Committee. Circulation 114, 82-96.

51. US Department of Health and Human Services \& US Department of Agriculture (2015) 2015-2020 Dietary Guidelines for Americans, 8th ed. Washington, DC: DHHS and USDA; available at https://health.gov/dietaryguidelines/ 2015/guidelines/

52. Economos CD, Folta SC, Goldberg J et al. (2009) A community-based restaurant initiative to increase availability of healthy menu options in Somerville, Massachusetts: Shape Up Somerville. Prev Chronic Dis 6, A102.

53. Green KL, Steer SL, Maluk RE et al. (1993) Evaluation of the heart smart restaurant program in Saskatoon and Regina, Saskatchewan. Can J Public Health 84, 399-402.

54. Urban LE, Lichtenstein AH, Gary CE et al. (2013) The energy content of restaurant foods without stated calorie information. JAMA Intern Med 173, 1292-1299. 